\title{
Remote transplantation of a third ventricle colloid cyst: case report
}

\author{
Samira Zabihyan, MD, ${ }^{1}$ Hamid Etemadrezaie, MD, ${ }^{1}$ Humain Baharvahdat, MD, ${ }^{1}$ \\ Aslan Baradaran, MD, 'Babak Ganjeefar, MD, ${ }^{1}$ Michael A. Bohl, MD, ${ }^{2}$ and Peter Nakaji, MD ${ }^{2}$ \\ 1Department of Neurological Surgery, Quaem Hospital, Mashhad University of Medical Sciences, Mashhad, Iran; and 2Division of \\ Neurological Surgery, Barrow Neurological Institute, St. Joseph's Hospital and Medical Center, Phoenix, Arizona
}

\begin{abstract}
The authors report the case of a 15-year-old girl with a third ventricle colloid cyst. She presented with prolonged headache, nausea, vomiting, and loss of visual acuity with bilateral papilledema. Computed tomography and MRI revealed severe biventricular hydrocephalus with transependymal periventricular fluid and a minimally enhancing cystic mass of the third ventricle. The patient was diagnosed with a colloid cyst and obstructive hydrocephalus, and endoscopic resection with ablation of the cyst remnant was performed. While attempting to extricate the cyst from the patient's head, control of the cyst was lost and the cyst fell into the lateral ventricle beyond the surgeon's view. Postoperative imaging showed that the cyst had settled in the right occipital horn. After 3 years of follow-up, imaging suggests growth of the cyst in its new position without necrosis or displacement on prone imaging.
\end{abstract}

http://thejns.org/doi/abs/10.3171/2014.9.JNS14864

KEY WORDS colloid cyst; endoscopy; complication; third ventricle; oncology

$\mathrm{C}$ OLLOID cysts are rare, benign tumors that classically occur in the anterior third ventricle and often cause obstructive hydrocephalus via occlusion of one or both foramina of Monro. Surgical removal of both symptomatic and asymptomatic lesions is indicated due to a well-reported risk of rapid neurological decline in affected patients, theoretically due to hypothalamic compression and/or acute obstructive hydrocephalus. Although open microsurgical resection has traditionally been the preferred approach, endoscopic resection is gaining in popularity as it has been shown to be equally efficacious and potentially less morbid than open microsurgery. $1,10,12,15,16,18,19,28,30,31$ Recurrence rates following both open and endoscopic approaches are very low for those patients who receive total cyst resection, with slightly higher rates of recurrence for patients in whom a cyst remnant is left ablated in situ..$^{7,17}$ This report describes the fate of a cyst that was resected and subsequently lost in the lateral ventricle during extraction from the brain. Follow-up imaging strongly suggests that the cyst was successfully transplanted to the occipital horn where it continues to grow. To the best of our knowl- edge, no similar case of a transplanted colloid cyst has been reported.

\section{Case Report}

History and Examination

A 15-year-old girl presented complaining of chronic headaches and 3 months of persistent nausea and vomiting. Her parents expressed concern that her vision had recently begun deteriorating and that her loss of visual acuity was affecting her performance in school. Funduscopic examination showed severe bilateral papilledema, and neuropsychiatric testing revealed impaired recent memory function. Plantar reflexes were extensor on both sides. Motor, sensory, and cranial nerve examinations were otherwise intact. Her family history was negative for any inheritable neoplastic disease process.

Initial Imaging

A nonenhanced head CT scan showed an isodense third 
ventricle cyst with associated severe hydrocephalus. Contrast-enhanced CT showed that the lesion enhanced homogenously. Magnetic resonance imaging demonstrated a well-defined cystic mass in the third ventricle that was hypointense on T1- and T2-weighted imaging, and that enhanced homogenously with contrast (Fig. 1).

\section{Surgical Treatment}

Using a rigid endoscope in a right-frontal parasagittal approach, the right lateral ventricle was entered and its landmarks were identified for surgeon orientation. After entering the right foramen of Monro, the cyst was found underneath the roof of the third ventricle. The cyst was incised and its colloid contents evacuated. Endoscopic bipolar coagulation of the cyst base was then performed, followed by detachment of the cyst wall from the roof of the third ventricle. While using a grasping forceps to attempt removal of the capsule, control of the cyst was lost and the cyst wall fell outside of the surgeon's view into the lateral ventricle. Despite attempts to retrieve the cyst wall using irrigation, positive visualization could not be obtained. Histopathological studies revealed that the cyst contents were strongly positive for periodic acid-Schiff stain.

\section{Postoperative Course}

Postoperatively the patient suffered from aseptic meningitis, confirmed via lumbar puncture and routine CSF studies. Otherwise she recovered well as her hydrocephalic symptoms and biventriculomegaly resolved without the need for CSF diversion. The cyst was found on postoperative MRI to be in the occipital horn of the right lateral ventricle (Fig. 2). The patient's neurological examination was normal on discharge. No new memory deficit was found on postoperative testing and she was able to successfully resume school. At 10 months following surgery, a noncontrast MR image showed the lesion to be $13 \mathrm{~mm}$ long (Fig. $3 \mathrm{~A}$ and $\mathrm{B}$ ), and a prone $\mathrm{CT}$ scan revealed no displacement of the cyst within the ventricle (Fig. 3C and D). Given that the cyst appeared to be asymptomatic in its new location, the decision was made to manage the patient conservatively and continue to follow her with observation and routine imaging. After 31 months of conservative observation, the cyst was found to be embedded in the ependymal lining of the occipital horn with persistent enhancement and interval growth (Fig. 4). The size of the lesion has fluctuated from $16 \mathrm{~mm}$ early after surgery, to $13 \mathrm{~mm}$ after 10 months, and finally $20 \mathrm{~mm}$ after 31 months. She was followed for 3 years with office visits and formal neuropsychological testing, and was always found to be asymptomatic.

\section{Discussion}

Colloid cysts are slow-growing histologically benign lesions that comprise approximately $0.5 \%-1 \%$ of all intracranial tumors. ${ }^{4-6,21}$ Although these lesions often pose interesting management challenges to the neurosurgeon, such as whether to treat ${ }^{25,26}$ and which approach to use if treatment is necessary, the possibility of a lost cyst capsule "metastasizing" to a new location is not generally considered a potential complication. High-grade tumors such as glioblastoma, medulloblastoma, and some forms of ependymoma are well known for their ability to metastasize

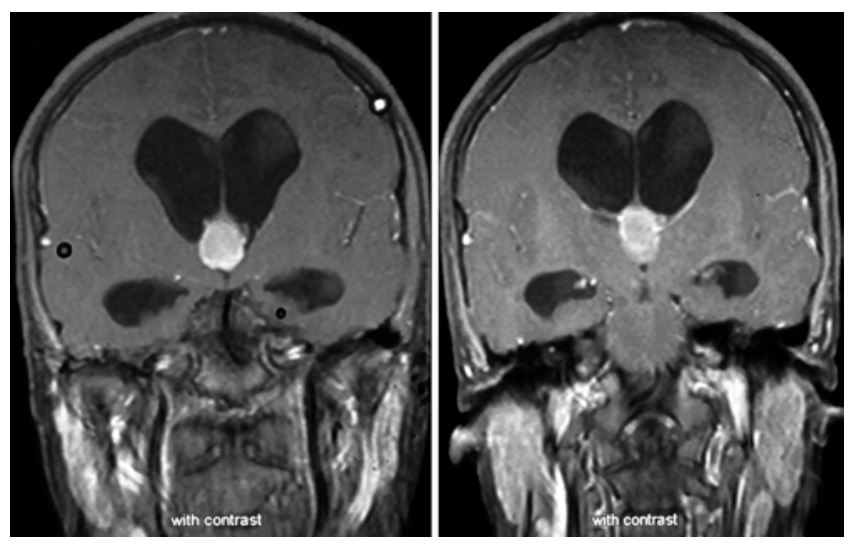

FIG. 1. Preoperative coronal T1-weighted MR images after Gd administration demonstrating a large cyst causing biventriculomegaly. The cystic lesion is within the third ventricle.

to remote locations. ${ }^{3,9,23}$ There are reports of high-grade gliomas spreading to remote cutaneous sites, ${ }^{11,22}$ or seeding stereotactic biopsy tracts. ${ }^{2,8,24,29}$ The presumed mechanism in these instances involves direct spreading of tumor cells during surgery. ${ }^{2}$ Some benign tumors such as craniopharyngioma have also been reported to be capable of spreading along surgical tracts or to distant sites via seeding of the CSF following surgery. ${ }^{27}$ However, there are no anecdotal case reports or series describing transplantation or metastasis of a colloid cyst. This report of a seemingly viable colloid cyst that has successfully reimplanted itself in a remote location following resection appears to be the first of its kind.

Although the etiology of colloid cysts continues to be debated, a leading theory is that these cysts are the result of ectopic endodermal cells that mistakenly migrated into the velum interpositum during embryonic development. Other intracranial cysts of endodermal origin include neurenteric cysts and Rathke cleft cysts, both prone to recurrence and the former capable of widespread dissemination..$^{32}$ Although any attempts at a possible pathophysiological mechanism of colloid cyst reimplantation is conjecture at this point, the reported ability of other endodermally derived intracranial cysts to "seed" distant metastases following surgical intervention suggests some property of endoderm-derived cells that may give them a predisposition to growth within the CNS. There are furthermore numerous reports in the literature of benign dermoid and epidermoid cysts "metastasizing" to distant locations, both intra- and extraventricular, following resection. ${ }^{13,20,33}$ This reported ability of ectoderm-derived cysts may similarly provide clues to the pathophysiology underlying the above case. Considering that dermoid and epidermoid cysts share a similar etiology (ectopic cells, in this case of ectodermal origin, mistakenly becoming entrapped in the CNS), it could be hypothesized that the mechanisms underlying colloid cyst reimplantation, neurenteric and Rathke cleft cyst recurrence, and dermoid/epidermoid recurrence are similar. Or, at least, that otherwise benign ectopic tissue of endodermal or ectodermal embryonic origin has a high propensity for implantation and growth within CNS tissue. 


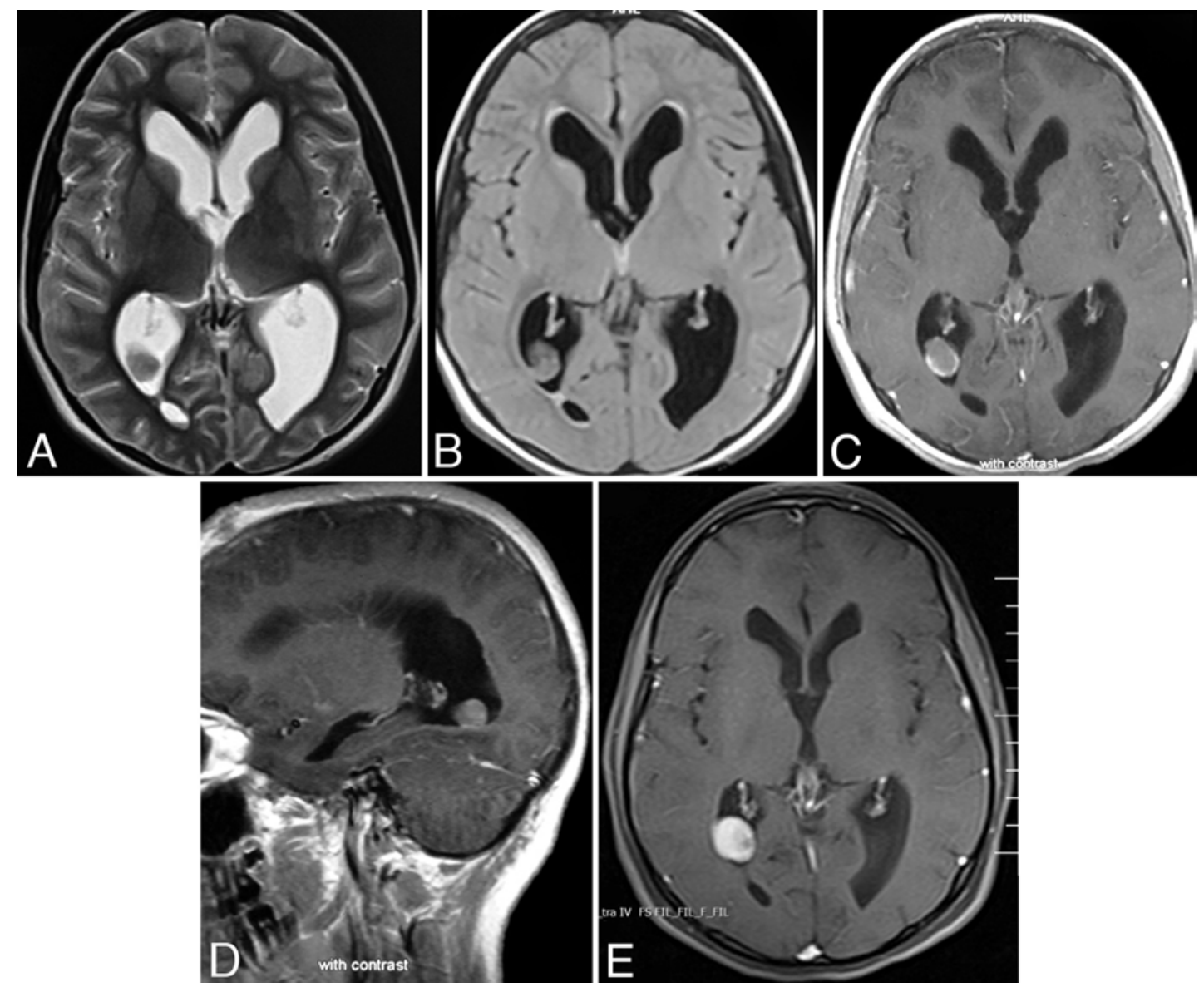

FIG. 2. Early (16-day) postoperative MR images showing the cyst in its new location (A-D), and the cyst diameter to be $16 \mathrm{~mm}$ (E). A: Axial T2-weighted. B: Axial FLAIR. C: Axial T1-weighted with Gd. D: Sagittal T1-weighted with Gd. E: Axial T1-weighted with contrast enhancement.

Interestingly, the literature contains a case report of neurocysticercosis mimicking colloid cyst. ${ }^{14}$ When these cysts are viable they are known to migrate throughout the ventricular system, sometimes causing obstructive hydrocephalus. Once the parasite degenerates, intraventricular larvae may adhere to the ependyma, typically causing focal ependymitis and ventriculitis. Although neurocysticercosis should certainly be kept on the differential for a case similar to that presented above, it is highly unlikely that the above case is one of neurocysticercosis considering the histopathological results, as well as the lack of ependymitis or septic meningitis/ventriculitis before or following surgery.

Inadvertent loss of the colloid cyst is not a desirable outcome. However, the event itself is easily imagined by anyone who has performed this procedure as the trajectory used in this approach does not easily afford exploration of the lateral ventricle. Irrigation was attempted in hopes of circulating the cyst back into view, but in this case it appears to have forced the cyst into the occipital horn. Immediate removal from another trajectory might have been considered, but as the cyst appeared to offer little risk in its new location, the decision was made to observe it. The fact that the cyst was able to stay alive and even grow is, if not surprising on biological grounds, at least noteworthy.
If any sign of mass effect or temporal horn entrapment occurs, a transcortical transatrial approach will be considered.

It is furthermore important to note that an imaging interval of 10 months following immediate postoperative MRI (as in this case) is too long, especially considering the potential for early occlusive hydrocephalus secondary to cyst migration. In any future cases of a colloid cyst becoming lost in the lateral ventricle following resection, we recommend immediate postoperative supine and prone imaging to assess for cyst migration potential. If the cyst is found to be mobile, the patient should be instructed to avoid prone positioning and to immediately present to an emergency department if they develop signs or symptoms of hydrocephalus. The patient should be followed with monthly supine and prone imaging until the cyst appears to have become immobile, at which time follow-up imaging can occur at longer intervals of 6 months and then yearly. The patient should still be reminded that they are at risk for developing occlusive hydrocephalus in the future and that if such symptoms develop, they should immediately present for a diagnostic workup. Surgical removal of a lost cyst should be strongly considered in any patient with a persistently mobile cyst, and necessary in any patient who becomes symptomatic from a mobile cyst that 


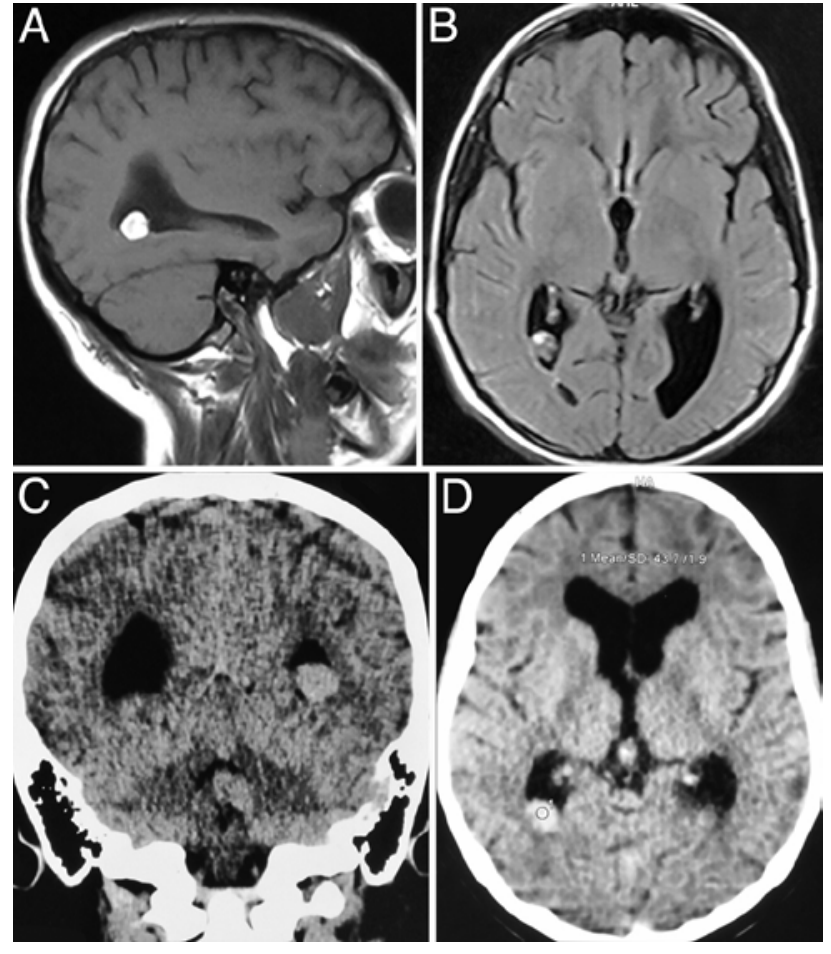

FIG. 3. Images obtained at 10 months following surgery. Sagittal (A) and axial (B) T1-weighted MR images showing the cyst to be $13 \mathrm{~mm}$ in diameter. Coronal (C) and axial (D) nonenhanced CT scans obtained with the patient prone showing that the cyst was embedded and immobile in the right occipital horn of the lateral ventricle.
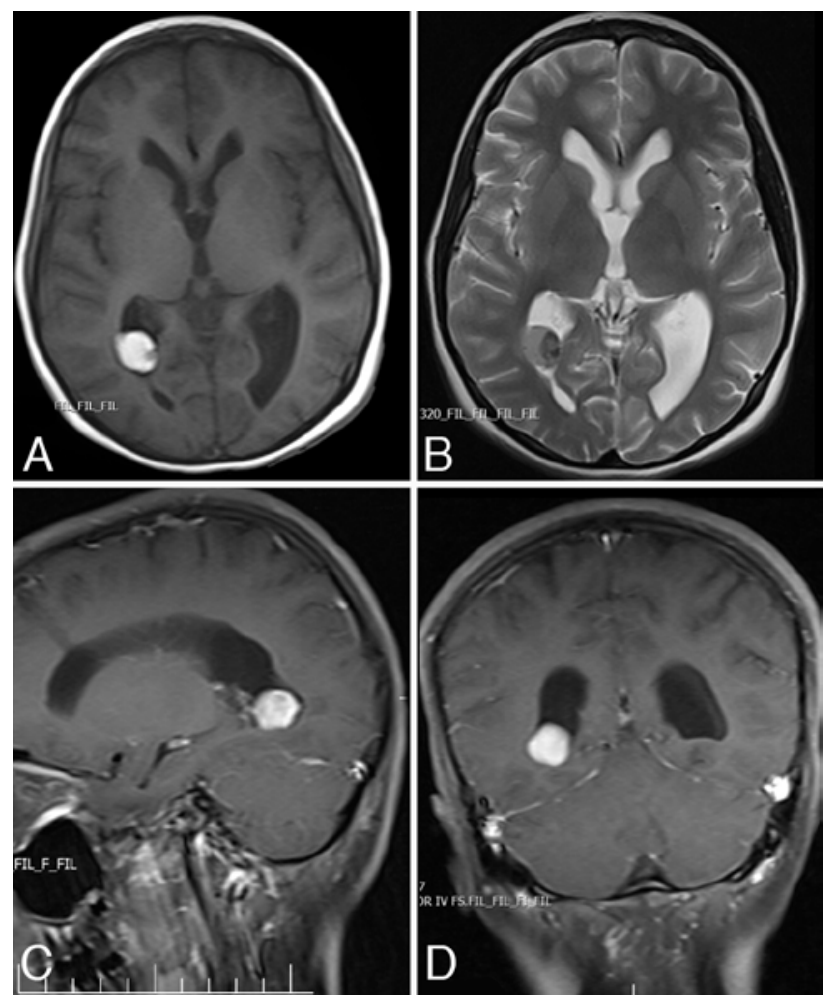

FIG. 4. Postoperative MR images at 31 months following surgery showing that the cyst remained in the right occipital horn, and the cyst diameter was $20 \mathrm{~mm}$. A: Axial T1-weighted without Gd. B: Axial T2-weighted. C: Sagittal T1-weighted with Gd. D: Coronal T1-weighted with Gd. may be causing intermittent or permanent obstructive hydrocephalus.

To the best of our knowledge, this is a singular and somewhat peculiar case in which an excised and subsequently lost colloid cyst was able to reimplant itself and grow in a remote location.

\section{References}

1. Abdou MS, Cohen AR: Endoscopic treatment of colloid cysts of the third ventricle. Technical note and review of the literature. J Neurosurg 89:1062-1068, 1998

2. Aichholzer M, Mazal PR, Haberler C, Dietrich W, Bertalanffy A, Roessler K, et al: Epidural metastasis of a glioblastoma after stereotactic biopsy: case report. Minim Invasive Neurosurg 44:175-177, 2001

3. Alvarez de Eulate-Beramendi S, Rigau V, Taillandier L, Duffau H: Delayed leptomeningeal and subependymal seeding after multiple surgeries for supratentorial diffuse low-grade gliomas in adults. J Neurosurg 120:833-839, 2014

4. Antunes JL, Louis KM, Ganti SR: Colloid cysts of the third ventricle. Neurosurgery 7:450-455, 1980

5. Batnitzky S, Sarwar M, Leeds NE, Schechter MM, Azar-Kia B: Colloid cysts of the third ventricle. Radiology 112:327341, 1974

6. Beems T, Menovsky T, Lammens M: Hemorrhagic colloid cyst: case report and review of the literature. Surg Neurol 65:84-86, 2006

7. Boogaarts HD, Decq P, Grotenhuis JA, Le Guérinel C, Nseir $\mathrm{R}$, Jarraya B, et al: Long-term results of the neuroendoscopic management of colloid cysts of the third ventricle: a series of 90 cases. Neurosurgery 68:179-187, 2011

8. Bouillot-Eimer S, Loiseau H, Vital A: Subcutaneous tumoral seeding from a glioblastoma following stereotactic biopsy: case report and review of the literature. Clin Neuropathol 24:247-251, 2005

9. Buis DR, van der Valk P, De Witt Hamer PC: Subcutaneous tumor seeding after biopsy in gliomatosis cerebri. J Neurooncol 106:431-435, 2012

10. Decq P, Le Guerinel C, Brugières P, Djindjian M, Silva D, Kéravel Y, et al: Endoscopic management of colloid cysts. Neurosurgery 42:1288-1296, 1998

11. Figueroa P, Lupton JR, Remington T, Olding M, Jones RV, Sekhar LN, et al: Cutaneous metastasis from an intracranial glioblastoma multiforme. J Am Acad Dermatol 46:297300, 2002

12. Gaab MR, Schroeder HW: Neuroendoscopic approach to intraventricular lesions. J Neurosurg 88:496-505, 1998

13. Guidetti B, Gagliardi FM: Epidermoid and dermoid cysts. Clinical evaluation and late surgical results. J Neurosurg 47:12-18, 1977

14. Gupta A, Nadimpalli SP, Cavallino RP: Intraventricular neurocysticercosis mimicking colloid cyst. Case report. J Neurosurg 97:208-210, 2002

15. Harris AE, Hadjipanayis CG, Lunsford LD, Lunsford AK, Kassam AB: Microsurgical removal of intraventricular lesions using endoscopic visualization and stereotactic guidance. Neurosurgery 56 (1 Suppl):125-132, 2005

16. Hellwig D, Bauer BL, Schulte M, Gatscher S, Riegel T, Bertalanffy H: Neuroendoscopic treatment for colloid cysts of the third ventricle: the experience of a decade. Neurosurgery 52:525-533, 2003

17. Hoffman CE, Savage NJ, Souweidane MM: The significance of cyst remnants after endoscopic colloid cyst resection: a retrospective clinical case series. Neurosurgery 73:233-239, 2013

18. Horn EM, Feiz-Erfan I, Bristol RE, Lekovic GP, Goslar PW, Smith KA, et al: Treatment options for third ventricular col- 
loid cysts: comparison of open microsurgical versus endoscopic resection. Neurosurgery 60:613-620, 2007

19. Kehler U, Brunori A, Gliemroth J, Nowak G, Delitala A, Chiappetta F, et al: Twenty colloid cysts-comparison of endoscopic and microsurgical management. Minim Invasive Neurosurg 44:121-127, 2001

20. Khan RB, Giri DD, Rosenblum MK, Petito FA, DeAngelis LM: Leptomeningeal metastasis from an intracranial epidermoid cyst. Neurology 56:1419-1420, 2001

21. Little JR, MacCarty CS: Colloid cysts of the third ventricle. J Neurosurg 40:230-235, 1974

22. Miliaras G, Tsitsopoulos PP, Markoula S, Kyritsis A, Polyzoidis KS, Malamou-Mitsi V: Multifocal glioblastoma with remote cutaneous metastasis: a case report and review of the literature. Cent Eur Neurosurg 70:39-42, 2009

23. Phi JH, Choi SA, Lim SH, Lee J, Wang KC, Park SH, et al: ID3 contributes to cerebrospinal fluid seeding and poor prognosis in medulloblastoma. BMC Cancer 13:291, 2013

24. Pierallini A, Caramia F, Piattella MC, Pantano P, Santoro A, Di Stefano D, et al: Metastasis along the stereotactic biopsy trajectory in glioblastoma multiforme. Acta Neurochir (Wien) 141:1011-1012, 1999

25. Pollock BE, Huston J III: Natural history of asymptomatic colloid cysts of the third ventricle. J Neurosurg 91:364-369, 1999

26. Pollock BE, Schreiner SA, Huston J III: A theory on the natural history of colloid cysts of the third ventricle. Neurosurgery 46:1077-1083, 2000

27. Schmalisch K, Beschorner R, Psaras T, Honegger J: Postoperative intracranial seeding of craniopharyngiomas-report of three cases and review of the literature. Acta Neurochir (Wien) 152:313-319, 2010

28. Schroeder HW, Oertel J, Gaab MR: Endoscope-assisted microsurgical resection of epidermoid tumors of the cerebellopontine angle. J Neurosurg 101:227-232, 2004
29. Steinmetz MP, Barnett GH, Kim BS, Chidel MA, Suh JH: Metastatic seeding of the stereotactic biopsy tract in glioblastoma multiforme: case report and review of the literature. J Neurooncol 55:167-171, 2001

30. Wait SD, Gazzeri R, Wilson DA, Abla AA, Nakaji P, Teo C: Endoscopic colloid cyst resection in the absence of ventriculomegaly. Neurosurgery 73 (1 Suppl Operative):ons39ons 47, 2013

31. Wilson DA, Fusco DJ, Wait SD, Nakaji P: Endoscopic resection of colloid cysts: use of a dual-instrument technique and an anterolateral approach. World Neurosurg 80:576-583, 2013

32. Yasuda M, Nakagawa H, Ozawa H, Inukai C, Watabe T, Mizuno J, et al: Disseminated neurenteric cyst. J Neurosurg Spine 9:382-386, 2008

33. You NK, Ahn JY, Hong CK, Lee KS: Ectopic ventricular recurrence of an epidermoid cyst in the middle fossa. J Clin Neurosci 15:578-580, 2008

\section{Author Contributions}

Acquisition of data: Nakaji, Zabihyan, Etemadrezaie, Baharvahdat, Baradaran, Ganjeefar. Analysis and interpretation of data: all authors. Drafting the article: all authors. Critically revising the article: all authors. Reviewed submitted version of manuscript: all authors. Study supervision: Nakaji.

\section{Correspondence}

Peter Nakaji, c/o Neuroscience Publications, Barrow Neurological Institute, St. Joseph's Hospital and Medical Center, 350 W. Thomas Rd., Phoenix, AZ 85013. email: neuropub@ dignityhealth.org. 